\title{
Perspective shifts of Korean evidentials and the effect of contexts *
}

\author{
Dongsik Lim \\ CCHS-CSIC
}

\author{
Chungmin Lee \\ Seoul National University
}

\begin{abstract}
In this paper we identify two types of the evidential perspective shifts (the evidence holder indicated by an evidential marker is different from the utterance of the sentence containing that evidential marker) in Korean, the shift in interrogatives and the shift in declaratives, and explain these two shifts by proposing specific lexical entries for Korean evidential markers without any significant revision of the existing theory of interrogatives or indexicals. We also discuss an implication of our proposal, especially with respect to the interaction between our lexical entry for the Korean direct evidential marker and the Korean long-distance anaphor caki.
\end{abstract}

Keywords: Evidential, Perspective Shift, Korean, long-distance anaphor caki

\section{Introduction}

This paper aims to discuss two types of evidential perspective shifts in Korean (Lim 2010, Lee C. 2011, among others), and to investigate its theoretical implications. By the term evidential perspective shift, we mean (1):

\section{(1) EVIDENTIAL PERSPECTIVE SHIFT}

The evidence holder indicated by an evidential marker is different from the utterer of the sentence containing that evidential marker.

To see what definition (1) means, consider the following two Korean examples in (2), where the direct perceptual evidential -te-is employed.

a. John-i ne-lul chac-te-ra.

John-NOM you-ACC look.for-DIR.EVI-DECL

'John looked for you.'

* We thank audiences in SALT 22 and in the internal colloquium of ILLA, CCHS-CSIC (June 20, 2012) for their comments and questions. This study is partially supported by the project Estructura eventiva y 'construcción' léxico-sintáctica de las oraciones. Teoría y experimentación (FF200907114) (Project leader: Professor Violeta Demonte, CCHS-CSIC), which the first author is a participating member of, and the Korean National Research Foundation Excellent Scholar Grant (10020090049), from which the second author was funded.

(C2012 Lim and Lee 
Perspective Shifts of Korean Evidentials

Implication: the speaker has direct evidence regarding the prejacent that John looked for the addressee.

b. John-i ne-lul chac-te-nya?

John-NOM you-ACC look.for-DIR.EVI-Q

'Did John look for you?'

Implication: the addressee ${ }_{i}$ is expected to answer whether John looked for her $_{i}$ based on her ${ }_{i}$ direct perceptual evidence.

In (2a) the utterer of the sentence is also the one who has the direct evidence regarding the prejacent: the utterer has directly perceived (via visual or auditory perception, for example) that John looked for the addressee. However, in (2b), as we can see in the implication the sentence carries, the utterer of (2b) does not have any direct evidence, but it is the addressee who is expected by the speaker to have direct perceptual evidence and to answer based on that evidence. Here we can see that the evidential perspective is shifted from the utterer's to the addressee's.

Previous studies on the evidential perspective shift (for example, see McCready 2007; also see origo shift in Garrett 2001 and interrogative flip in Tenny 2006, among others) mainly discuss the shift in questions, such as (2b). However, as far as we can see, they are not satisfactory to account for the shift in Korean in two respects. First, they predict that the evidential perspective shift in questions is optional, but in Korean this shift is obligatory (see Lim 2010: ch.4). Second, they do not consider the fact that Korean also shows the evidential perspective shift in declaratives (observed in Lee C. 2011, inter alia), the example of which is in (3):

(3) John-i Bill-ul chac-te-ray.

John-NOM Bill-ACC look.for-DIR.EVI-REP.EVI

'John looked for Bill.'

Implication: the source of the speaker's reportative evidence has direct perceptual evidence regarding the prejacent that John looked for Bill.

In (3), we can see that two evidentials - the direct perceptual evidential -te- and the indirect reportative evidential $-r a y^{1}$ — are used in a single sentence. Looking at the implication of (3) carefully, we can see that there is no shift with respect to the reportative evidential -ray, whereas we do have the shift with respect to the direct evidential -te- (the utterer of (3) does not have direct evidence but only has reportative evidence regarding the prejacent).

This paper aims to analyze these two types of the evidential perspective shifts in Korean, without significantly revising the existent theories of indexicals (such as

1 We simply treat -tay as an allomorph of -ray, and for simplicity we will continue to use -ray. See also Lim 2010 which argues that a pre-final - $t a$ - is an indirect/reportative evidential marker. 
Kaplan 1989) or questions (such as Hamblin 1973 and Karttunen 1977). Specifically, we will show that two types of shifts can be easily accounted for by simply assuming that Korean evidentials are operators binding and overwriting the context parameter of the prejacent (cf. Anand \& Nevins 2004). After explaining two types of shifts, we will also discuss the theoretical implication of our proposal, especially with respect to an interaction between evidentials and the Korean long-distance anaphor caki.

This paper is organized as follows. In Section 2 we analyze the evidential perspective shift in questions. Here we briefly illustrate Lim's (2010) proposal we essentially adopt, and explain how his proposal accounts for the perspective shift in questions with Korean direct evidential -te-. Next, in Section 3, we extend Lim's (2010) proposal to the case of the shift in declaratives, and explain it by assuming the same type for the lexical entry of -ray as the lexical entry of -te-. In Section 4 we discuss how our proposal of Korean evidentials as context-overwriting operator accounts for the exceptional licensing of the logophor caki in Korean, the problem first pointed out by Lim (to appear). In Section 5 we conclude the paper and discuss remaining problems.

\section{The perspective shift in questions}

In this section we discuss the evidential perspective shift in questions. Before presenting our analysis, however, we introduce the theoretical assumptions we adopt.

\subsection{Theoretical assumptions}

First, we adopt Kaplan's (1989) theory of indexicals, where a context is a tuple of the world, the time, the utterer, and the addressee of a sentence:

$$
c=<w, t, u, a>
$$

A sentence is a function from contexts to intensions (which he calls a character), and an intension is a function from worlds to truth-values. Indexicals are assumed to directly receive their denotation from the context. Therefore, if we call $c^{*}$ the context of the utterance, and UTTERER and ADDRESSEE functions taking a context and returning the utterer and the addressee in that context, respectively, then the denotation of the 1 st person pronoun $n a$ and the 2 nd person pronoun $n e$ in $c^{*}$ is the utterer and the addressee of $c^{*}$, that is $u^{*}$ and $a^{*}$, respectively, as shown in (5):
a. $c^{*}=\left\langle w^{*}, t^{*}, u^{*}, a^{*}>\right.$
b. $\llbracket n a \rrbracket^{c^{*}, w^{*}}=\operatorname{UTTERER}\left(c^{*}\right)=u^{*}$
c. $\llbracket n e \rrbracket^{c^{*}, w^{*}}=\operatorname{ADDRESSEE}\left(c^{*}\right)=a^{*}$ 
Second, we assume the (rather standard) semantics of questions, first proposed by Hamblin (1973) and then Karttunen (1977), according to which the denotation of a question is the set of its possible answers. Specifically we adopt Hamblin (1973), and assume that we derive a set of answers from a proposition on behalf of the semantics of wh-words. For example, who denotes a set of persons (see 6a), and whether, which appears in yes-no questions (either overtly or covertly), denotes a set of two functions, one taking a proposition and returning the same proposition, and the other taking a proposition and returning its negation (which we simplify as identity function and negation function, as in 6b):

$$
\begin{aligned}
& \text { a. } \llbracket w h o \rrbracket=\left\{x_{e}: x \text { is a person }\right\} \\
& \text { b. } \llbracket w h e t h e r \rrbracket=\left\{\lambda p_{s t} \cdot p_{s t}, \lambda p_{s t} . \sim p_{s t}\right\}\left(\text { or }\left\{\mathrm{ID}_{<s t, s t>}, \mathrm{NEG}_{<s t, s t>}\right\}\right)
\end{aligned}
$$

Since here wh-words denote a set of individuals, properties, or functions taking propositions, we find cases where either functions are in a set, arguments are in a set, or both arguments and functions are in different sets, as shown in (7). In these cases the regular functional application does not apply. To avoid this problem, we introduce a new compositional rule, that is Pointwise Functional Application (PFA) (first assumed by Hamblin (1973) and rendered by Heim \& von Fintel (2001) as 8):
a. $\left[\left[\alpha_{<\sigma, \tau>}\right]\left[\left\{\beta: \beta \in \mathrm{D}_{\sigma}\right\}\right]\right]$
b. $\left[\left[\left\{\alpha: \alpha_{<\sigma, \tau>}\right\}\right]\left[\beta \in \mathrm{D}_{\sigma}\right]\right]$
c. $\left[[\{\alpha: \alpha<\sigma, \tau>\}]\left[\left\{\beta: \beta \in \mathrm{D}_{\sigma}\right\}\right]\right]$

Pointwise Functional Application (PFA) (from Heim \& von Fintel 2001)

If $\alpha$ is a branching node and $\{\beta, \gamma\}$ is the set of its daughters, then $\llbracket \alpha \rrbracket_{c}=$
a. $\lambda w \cdot \llbracket \beta \rrbracket_{c^{c}}(w)\left(\llbracket \gamma \rrbracket_{c^{\prime}}(w)\right)$ or
b. $\left\{\lambda w \cdot \llbracket \beta \rrbracket_{C}(w)(x(w)): x \in \llbracket \gamma \rrbracket_{C}\right\}$ or
c. $\left\{\lambda w \cdot f(w)\left(\llbracket \gamma \rrbracket_{C^{\prime}}(w)\right): f \in \llbracket \beta \rrbracket_{C_{C}}\right\}$ or
d. $\left\{\lambda w \cdot f(w)(x(w)): f \in \llbracket \beta \rrbracket_{c} \& x \in \llbracket \gamma \rrbracket_{C_{C}}\right\}$

whichever is defined.

With the PFA defined in (8), we can derive a set of type $\tau$ from each tree in (7).

\subsection{Explaining the shift in questions}

Now we are ready to introduce our analysis of the evidential perspective shift in questions. We essentially adopt Lim's (2010, in preparation) analysis, according to 
which a question including an evidential marker denotes a set of characters, rather than a set of propositions. According to Lim (2010), this can be done by assuming that Korean evidentials are functions from propositions to characters, introducing a variable over contexts. Following this analysis, we propose that Korean evidentials overwrite the context parameter against which the prejacent is evaluated (see also Anand \& Nevins 2004 and McCready 2007). Under our analysis, for example, the lexical entry for the direct perceptual evidential -te- is (9):

(9) For any utterance context $c^{*}$, any world of evaluation $w^{*}$, and the prejacent $\phi$ of type $<s, t>$ :

$\llbracket-t e-\rrbracket^{c^{*}, w^{*}}\left(\llbracket \phi \rrbracket^{c^{*}, w^{*}}\right)=\lambda c$ : UTTERER $(c)$ has direct perceptual evidence regarding $\phi . \lambda w \cdot \llbracket \phi \rrbracket^{c, w}$

According to (9), -te- takes a proposition as its argument, returns a character and overwrites the utterance context $c^{*}$ with the new context $c$ which by itself is bound. We also assume that -te- also introduces the definedness condition (that is presupposition), according to which the utterer in $c$ has direct perceptual evidence regarding the prejacent. $^{2}$

Let us see how the lexical entry in (9) explains the evidential perspective shift in interrogatives with the example in (10):

John-i na-lul chac-te-nya?
John-NOM I-ACC look.for-DIR.EVI-Q

'Did John look for me?'

Implication: the utterer expects the addressee to answer whether John looked for the utterer based on the addressee's direct perceptual evidence.

We assume that the LF of (10) is (11), where the first person pronoun na denotes the utterer in $c^{*}$ and -te- takes wide scope over covert whether: $^{3}$

2 As Murray (2009) rightly points out, a problem of this analysis is that evidentials seem to introduce new information regarding the speaker's evidence to the common ground (CG). Although we acknowledge this problem, for simplicity in computation, we will keep assuming that -te-is a presupposition trigger (see also Schlenker 2007, arguing that some presuppositions may introduce new information to the $\mathrm{CG}$ ). We do not deal with the question of whether -te-is an epistemic modal or not either, but unlike what Lee J. (2010) argues, we believe that there is not enough evidence supporting the claim that -te-is an epistemic modal (see Lim 2010 and Lee C. 2011 for further arguments).

3 At first sight this LF seems counterintuitive, but as argued by Lim (2010), this choice is purely due to semantic computation. Suppose that -te-takes narrow scope with respect to whether. Then the sister node of whether would denote a character, whereas each function in the denotation of whether needs to combine with a proposition, resulting in type-mismatch. 
Perspective Shifts of Korean Evidentials

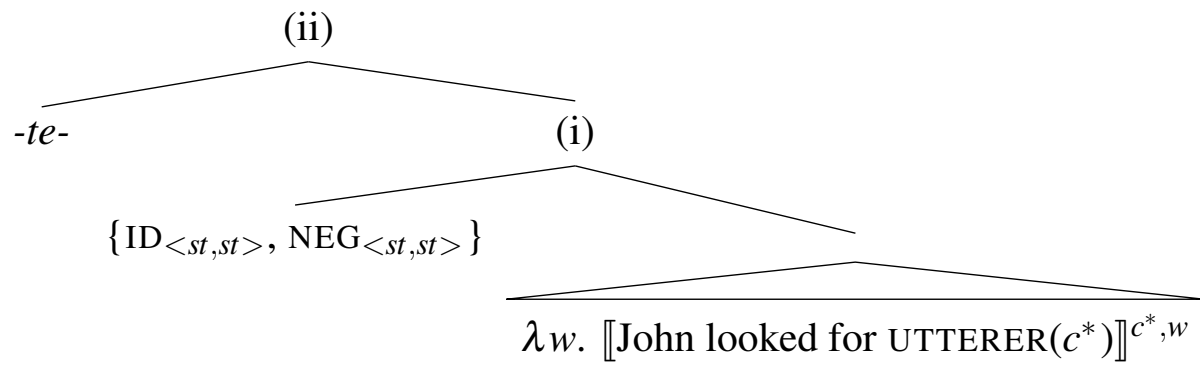

The denotation at node (i) in (11) is (12), which is obtained by combining each function in the denotation of whether with the proposition that John looked for the utterer in $c^{*}$ via PFA (8b):

$$
\begin{aligned}
\llbracket(i) \rrbracket^{c^{*}, w^{*}}= & \left\{\lambda w \cdot \llbracket \text { John looked for } \operatorname{UTTERER}\left(c^{*}\right) \rrbracket^{c^{*}, w},\right. \\
& \left.\lambda w \cdot \llbracket \text { John did not look for } \operatorname{UTTERER}\left(c^{*}\right) \rrbracket^{c^{*}, w}\right\}
\end{aligned}
$$

Two functions in (12) correspond to the affirmative answer and the negative answer, respectively. Now, these two functions combine with -te-via PFA (8c), as in (13):

$$
\begin{aligned}
& \llbracket(\text { ii }) \rrbracket^{c^{*}, w^{*}}= \\
& \llbracket \text {-te- } \rrbracket^{c^{*}, w^{*}}\left(\left\{\lambda w \text {. } \llbracket \text { John looked for UTTERER }\left(c^{*}\right) \rrbracket^{c^{*}, w},\right.\right. \\
& \left.\left.\lambda w . \llbracket \text { John did not look for } \operatorname{UTTERER}\left(c^{*}\right) \rrbracket^{c^{*}, w}\right\}\right) \\
& =\left\{\llbracket-t e-\rrbracket^{c^{*}, w^{*}}\left(\lambda w \cdot \llbracket \text { John looked for UTTERER }\left(c^{*}\right) \rrbracket^{c^{*}, w}\right)\right. \text {, } \\
& \left.\llbracket-t e-\rrbracket \rrbracket^{c^{*}, w^{*}}\left(\lambda w . \llbracket \text { John did not look for } \operatorname{UTTERER}\left(c^{*}\right) \rrbracket^{c^{*}, w}\right)\right\}
\end{aligned}
$$

Finally, applying the lexical entry for -te- in (9), we obtain (14), a set of two characters where the context parameter $c^{*}$ in the prejacent is overwritten by the context variable $c$ introduced by $-t e-$ :

$$
\llbracket(\text { ii) }) \rrbracket^{c^{*}, w^{*}}=
$$

$\{\lambda \mathrm{c}$ : UTTERER $(c)$ has direct perceptual evidence re. the prejacent that John looked for $\operatorname{UTTERER}\left(c^{*}\right): \lambda w$. $\llbracket$ John looked for $\operatorname{UTTERER}\left(c^{*}\right) \rrbracket^{c, w}$, $\lambda \mathrm{c}$ : UTTERER $(c)$ has direct perceptual evidence re. the prejacent that J. did not look for $\operatorname{UTtERER}\left(c^{*}\right): \lambda w$. $\llbracket \mathrm{J}$. did not look for $\left.\operatorname{UTTERER}\left(c^{*}\right) \rrbracket^{c, w}\right\}$

To see how (14) explains the shift in questions, suppose an utterer asks the question in (10). In Hamblin's (1973) theory of questions, this means that the utterer presents a set of (possible) answers (that is (14)) to the addressee. However, since the entire set of answers is presented, none the answers in (14) are directly uttered by the utterer: each answer can be uttered only when the addressee chooses it as his/her true answer.

Now, consider each answer in (14). In each answer, the evidential presupposition is anchored to the variable $c$, which is still bound. Since none of the answers 
in (14) is directly uttered by the utterer, the variable $c$ cannot be saturated by the utterer's context, which means that this presupposition cannot be anchored to the utterer. The utterer can only expect that one of these presuppositions will be anchored to the addressee when he/she chooses one of the answers as his/her true answer: when one of these answers (which are characters) is uttered by the addressee, it applies to the addressee's context, and then the presupposition is anchored to the utterer in the addressee's context, or the addressee.

Summarizing the discussion above: we have shown that our lexical entry for Korean evidentials, a function from propositions to characters, accounts for the evidential perspective shift in questions without any further stipulation in the semantics of questions or indexicals. In the next section, we will extend this idea to the evidential perspective shift in declaratives.

\section{The perspective shift in declaratives}

To account for the shift in declaratives, we first need to understand what the nature of the reportative evidential -ray might be, since intuitively what seems to be responsible for the shift in declaratives such as (3) is the semantics of -ray rather than the semantics of -te- (which in fact shows the shift). Specifically we investigate the construction containing -te- and -ray in comparison with the construction containing the verb of saying (mal)ha-, which apparently introduces an implication similar to that of -ray.

\subsection{The nature of -ray}

Our question here is whether the sentence containing -ray is a quotation construction or not (this amounts to asking whether -ray is actually a reportative evidential or a phonological contraction of the verb of saying $h a-$ ). The answer seems to be mixed. First, as pointed out by Anand \& Nevins (2004), one of the characteristics of the quotative construction is that it does not allow A'-extraction, that is, it is not allowed to form a wh-question by extracting a wh-word from the embedded sentence (or the prejacent). (15) shows that we cannot make a wh-question from the prejacent of -te-ray, which means that $\mathrm{A}^{\prime}$-extraction is not possible under -te-ray. ${ }^{4}$

4 Each question in (15) has two readings depending on how the wh-word $n w u(k w u)$ 'who' is interpreted: in one reading, $n w u(k w u)$ is interpreted as a wh-word, but in the other reading, $n w u(k w u)$ is interpreted as an indefinite pronoun 'someone'. In the first reading each question is interpreted as a wh-question (hereafter the wh-question reading), whereas in the second reading each question is interpreted as a yes/no question (hereafter the yes/no question reading). The yes/no question reading is available for both questions, but this is irrelevant of our discussion. Actually, the two authors of this paper diverge in judgments of (15): one author thinks two sentences in (15) can have either the wh-question reading or the yes/no question reading, while the other author thinks only the yes/no 
Perspective Shifts of Korean Evidentials

a. ??Nwu-ka Mary-lul chac-te-ray? who-NOM Mary-ACC look.for-DIR.EVI-REP.EVI-DECL

b. ??John-i nwukwu-lul chac-te-ray? John-NOM who-ACC look.for-DIR.EVI-REP.EVI-DECL

This suggests to us that the sentence containing -te-ray is similar to the quotative construction rather than the construction involving evidentials. Note that -te-generally does not appear in embedded sentences, as shown in (16):

John-un pi-ka o-te-la-ko ?malhayssta /
John-TOP rain-NOM fall-DIR.EVI-DECL-COMP said
??sayngkakhayssta / ??cwucanghayssta / ??pokohayssta...
thought
/ claimed / reported...

(Intended) 'John said/thought/claimed/reported... that it rained.' (with direct evidential implication anchored to John)

Some authors, including Lee J. (2010), claim that examples like (16) are acceptable, but we think that this kind of judgment is due to the confusion between embedding and quotation. As far as we can see, -te-can appear in embedded sentences when the main verb is the verb of saying, which means that the cases where -te- appears in an embedded position are actually instances of quotation, not embedding. Our claim is further supported by the fact that $\mathrm{A}^{\prime}$-extraction from embedded sentences with -te- is impossible, as shown in $(17):^{5}$

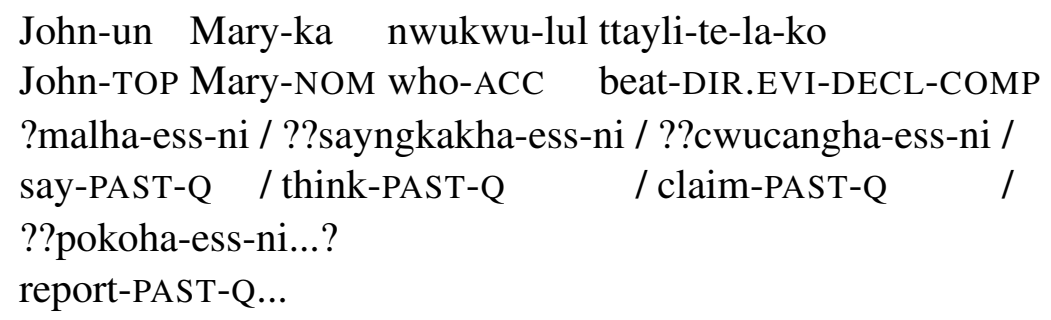

(Intended) 'Who did John say/think/claim/report Mary beat?' (with direct evidential implication anchored to John)

From these examples, one might be tempted to conclude that the example with the ending - ray is an instance of quotation, and - ray is a phonological contraction of the

question reading is available in both questions. However, both agree that the yes/no question reading is more easily available in both questions than the wh-question reading.

5 The judgments again vary depending on speakers. In general the verb of saying ( $m a l$ )ha- 'say' seems to allow -te- in the embedded position more easily, as pointed out by Chung (2010), among others, and other verbs do not seem to allow -te- as easily as the verb of saying. We will not pursue this issue any deeper. 
verb of saying, or at least includes a covert verb of saying (Chae 2006). However, this conclusion seems too hasty, given that -ray allows $\mathrm{A}^{\prime}$-extraction as well as exhibits perspective shifts in questions when used without -te-, as in (18):

a. John-i nwukwu-lul chac-ass-tay?

John-NOM who-ACC look.for-PAST-REP.EVI?

'Who did John look for?' (with evidential implication anchored to the addressee)

b. Nwukwu-ka Mary-lul chac-ass-tay?

who-NOM Mary-ACC look.for-PAST-REP.EVI?

'Who looked for Mary?' (with evidential implication anchored to the addressee)

Furthermore, if -ray contained a verb of saying, this verb could be the target of negation, but as shown in (19a), -ray cannot be the target of negation, unlike the verb of saying in $(19 b)$ :

a. ??John-i Mary-lul chac-te-ray-cianh-ass-e.

John-NOM Mary-ACC look.for-DIR.EVI-REP.EVI-NEG-PAST-DECL

b. (Bill-un) "John-i Mary-lul chac-te-la"-ko

(Bill-TOP) John-NOM Mary-ACC look.for-DIR.EVI-DECL-COMP

ha-cianh-ass-e.

say-NEG-PAST-DECL

(roughly) 'Bill did not say "(I saw that) John looked for Mary”.'

In conclusion, at the moment it is still unclear whether -ray is a true evidential (or expressing evidentiality in the narrow sense) or just a phonological contraction of a verb of saying (or expressing evidentiality in the broad sense). ${ }^{6}$ If the latter is the case, we should assume a complex sentence including the verb of saying (as argued in Lee C. 2011, particularly in non-declarative speech acts such as interrogatives, imperatives and propositives/exhortatives). Although here we assume that -ray is an evidential marker different from the verb of saying, given examples like (18) and (19) (see also Lim 2010: ch.4), below we will also argue that the lexical entry for -ray contains semantic components comparable with those of the verb of saying.

\subsection{Explaining the shift in declaratives}

Tentatively, let us assume the following lexical entry for -tay/lay:

6 See Lim 2010: ch.1 for the distinction between narrow evidentiality and broad evidentiality. 
Perspective Shifts of Korean Evidentials

(20) For any context $c^{*}$ and any world of evaluation $w^{*}$ :

$\llbracket-r a y \rrbracket^{c^{*}, w^{*}}=$

$\lambda k_{<c, s t>} . \lambda c_{c}: \exists c^{\prime}$ s.t. UTTERER $\left(c^{\prime}\right)$ said to UTTERER(c) that $k\left(c^{\prime}\right)$.

$\lambda w \cdot \llbracket k\left(c^{\prime}\right)(w) \rrbracket^{c, w}$

According to this lexical entry, -ray takes a character $k$ as its argument, and returns another character, with the following definedness condition: there is another context $c^{\prime}$ who uttered the proposition $k\left(c^{\prime}\right)$. This means that the character $k$, which is the argument of -ray, first needs to apply to context $c^{\prime}$, returning a proposition $k\left(c^{\prime}\right)$. This proposition again becomes a character by binding the context $c$ with an operator. This context $c$ also has the definedness condition, according to which the utterer of this context $c$ has reportative evidence from the utterer in $c^{\prime}$.

Now let us illustrate how (20) accounts for the perspective shift in declaratives with example (21) (repeated from (3)):

John-i Bill-ul chac-te-ray.
John-NOM Bill-ACC look.for-DIR.EVI-REP.EVI

'John looked for Bill.'

Implication: the source of the speaker's reportative evidence has direct perceptual evidence regarding the prejacent that John saw Mary.

First, the prejacent of (21) is (22), which is a proposition:

(22) $\lambda w \cdot \llbracket J o h n$ looked for Bill $\rrbracket^{c^{*}, w}$

-te- applies to this prejacent, returns a character:

$\llbracket-t e-\rrbracket c^{c^{*}, w^{*}}\left(\lambda w \cdot \llbracket\right.$ John looked for Bill $\left.\rrbracket \rrbracket^{c^{*}, w}\right)$

$=\lambda c$ : UTTERER $(c)$ has direct perceptual evidence regarding the prejacent that John looked for Bill. $\lambda w$. 【John looked for Bill $\rrbracket^{c, w}$

-ray applies to the character in (23):

$\llbracket-r a y \rrbracket \rrbracket^{*}, w^{*}(\lambda c$ : UTTERER $(c)$ has direct perceptual evidence regarding the prejacent that John looked for Bill. $\lambda w$. $\llbracket$ John looked for Bill $\left.\rrbracket^{c, w}\right)=$

$\left[\lambda k_{<c, s t>} . \lambda c_{c}: \exists c^{\prime}\right.$ s.t. UTTERER $\left(c^{\prime}\right)$ said to UTTERER $(c)$ that $k\left(c^{\prime}\right)$.

$\left.\lambda w \cdot \llbracket k\left(c^{\prime}\right)(w) \rrbracket^{c, w}\right](\lambda c$ : UTTERER $(c)$ has direct perceptual evidence regarding the prejacent that John looked for Bill. $\lambda w$. $\llbracket$ John looked for Bill $\rrbracket^{c, w}$ )

Computing (24), we have the character (25):

(25) $\lambda c$ : (definedness condition in (26)). $\lambda w . \llbracket$ John looked for Bill $\rrbracket^{c, w}$ )

(25) has the following two definedness condition: 
a. $\exists c^{\prime}$ s.t. UTTERER $\left(c^{\prime}\right)$ has direct perceptual evidence regarding the prejacent that John looked for Bill (from the definedness condition introduced by -te-)

b. the UTTERER $\left(c^{\prime}\right)$ said to UTTERER $(c)$ that John looked for Bill (from the definedness condition introduced by -ray)

These two definedness conditions explain the shift in declaratives. First, the character $k$ applies to the context $c^{\prime}$ first, which is existentially bound, and the definedness condition introduced by -te- becomes the definedness condition of $c^{\prime}$, meaning that the utterer in $c^{\prime}$ should have the direct perceptual evidence regarding the prejacent (see (26a)). However, the utterer in $c^{\prime}$ is different from UTTERER(c), to whom the utterer in $c^{\prime}$ told the prejacent (see (26b)). Since the direct evidence holder (the utterer in $c^{\prime}$ ) is different from the reportative evidence holder (the utterer in $c$ ), we have the perspective shift.

Before concluding this section, we need to address two issues. First, as shown in (18), for example, -ray can apparently apply to a prejacent without -te-. Does this mean that -ray can also apply to a proposition? If not, how do we resolve this potential type-mismatch? To answer this question, we adopt Lim's (2010) proposal, and assume that there is a phonologically null type-shifter, or a phonologically covert evidential which is used 'by default', possibly introducing the implication that the speaker's assertion is based on his/her best possible grounds. The lexical entry for this default evidential will look like (27) (compare this with the lexical entry for -tein (9)):

$\llbracket$ NULL-EVI $\rrbracket^{c^{*}, w^{*}}\left(\llbracket \phi \rrbracket^{c^{*}, w^{*}}\right)=\lambda c$ : UTTERER $(c)$ asserts $\phi$ based on his/her best possible grounds. $\lambda w . \llbracket \phi \rrbracket^{c, w}$

Second, we argued that the result of applying a Korean evidential - either -te- or -ray to a prejacent is a character. However, this character still needs to become a proposition in a given utterance context $c^{*}$. We assume that this can be done by a declarative ending, ${ }^{7}$ which is plausible given that Korean declarative endings vary depending on the utterance context (specifically, depending on the social status of the utterer and the addressee as well as the register, which is analyzed in terms of the definedness condition in Lim 2010). According to this assumption, the lexical entry for the declarative ending in Korean is as follows (we omit the definedness condition for the social statuses of conversational participants and the register):

$$
\llbracket \mathrm{DECL} \rrbracket^{c^{*}, w^{*}}=\lambda k_{<c, s t>} \cdot k\left(c^{*}\right)
$$

In cases of -ray, which can appear in the position of the declarative ending, we further assume that the declarative ending is $-a / e$, which is phonologically contracted.

7 We also assume that the question ending plays a similar role: see Lim 2010: ch.5. 
Perspective Shifts of Korean Evidentials

\section{Context overwriting and the Korean long-distance anaphor caki}

In this section we argue that the idea that Korean evidentials show context overwriting effect can account for the puzzle regarding the interaction between Korean long-distance anaphor caki and Korean direct perceptual evidential -te-, first noticed by Lim (to appear).

\subsection{Puzzle}

It is known that Korean anaphor caki can be used as a long-distance anaphor referring to the attitude holder in the main predicate when the attitude holder has the relevant self-knowledge (hereafter de se knowledge). For example, (29) is felicitous only when Pavarotti knows that the singer who he thinks is a genius is actually Pavarotti himself: it is infelicitous when Pavarotti does not know that the singer is Pavarotti himself.

$$
\begin{aligned}
& \text { Pavarotti } i \text {-nun caki } i_{i} \text {-ka chenjay-la-ko sayngkakha-ess-ta. } \\
& \text { Pavarotti-TOP self-NOM genius-DECL-COMP think-PAST-DECL }
\end{aligned}
$$

'Pavarotti thought that he is a genius.'

However, Lim (to appear) observes that there are several cases where caki can be used as a long-distance anaphor even when the attitude holder does not have de se knowledge. Consider the scenario (30) from Lim to appear.

(30) Bill and John are close friends. Their children are also close friends, and go to the same school. Once Bill and John were invited to the school. In the school, when both Bill and John were observing a class from a distance, they saw a child causing trouble during class. After class, Bill asks Tom, the teacher, to scold that child, not knowing that he was his own son. John, however, noticed this. He says later...

In this scenario, the attitude holder is Bill, who does not have the relevant de se knowledge (he does not know that the troubling kid is actually his son). In contrast, the utterer is John, who has knowledge about the relation between Bill and the troublesome kid. This said, consider two examples in (31) (again from Lim to appear):

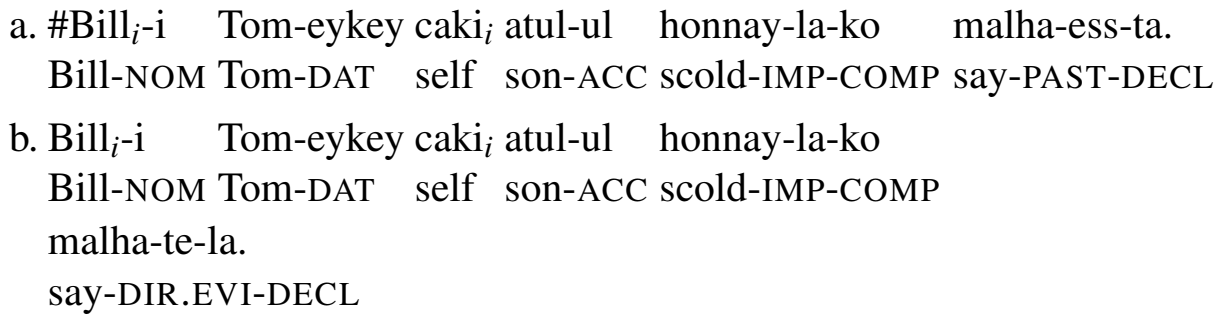

a. \#Bill $i_{i}$ - $\quad$ Tom-eykey caki $i_{i}$ atul-ul honnay-la-ko malha-ess-ta. Bill-NOM Tom-DAT self son-ACC scold-IMP-COMP say-PAST-DECL

b. Bill ${ }_{i}$-i Tom-eykey caki $i_{i}$ atul-ul honnay-la-ko Bill-NOM TOM-DAT self son-ACC scold-IMP-COMP malha-te-la. say-DIR.EVI-DECL 
'Bill $i_{\text {told Tom to scold self }}$ 's son.'

Implication: the utterer (John) saw Bill told Tom to scold his own son.

As indicated, (31a) is infelicitous under the scenario (30), which is expected: the attitude holder Bill does not know that the troublesome kid is his son, and therefore does not have the relevant de se knowledge. However, (31b) with the direct perceptual evidential -te-can be used felicitously even in the given scenario. This fact requires a semantic account.

Not only caki, but also PRO (which is only used as de selde te anaphor: see Chierchia 1989, among others) can be exceptionally licensed under -te- (Hoe in preparation). Consider the following scenario (revised from Anand 2006: 16):

(32) Bill is hosting a party. He hears that a certain waiter named Tom is being a nuisance. Now Bill tells the nearest waiter, "Tom has to go." However, John, a guest of the party, noticed that the waiter Bill is talking to is actually Tom. John later said to someone else...

Similarly to (30), the attitude holder Bill does not have the relevant de te knowledge, but the utterer John knows that the addressee Bill was talking to is actually Tom himself. In this case, (33a) shows that PRO is not licensed, as expected, but (33b) also shows PRO can be licensed when -te- is used.

a. \#Bill $i_{i}$ i Tom $_{j}$-eykey $\mathrm{PRO}_{j}$ ttena-la-ko malha-ess-ta. Bill-NOM Tom-DAT PRO leave-IMP-COMP say-PAST-DECL

b. Bill $_{i}$-i $\quad$ Tom $_{j}$-eykey $\mathrm{PRO}_{j}$ ttena-la-ko malha-te-la. Bill-NOM Tom-DAT PRO leave-IMP-COMP say-te-DECL

'Bill told Tom to leave.'

Implication: the utterer (John) saw that Bill told Tom to leave.

These examples suggest to us that the presence of -te- is responsible for the exceptional licensing of de selde te anaphors such as caki and PRO. In the next subsection, we will briefly outline our (tentative) analysis of this puzzle, with a complete analysis with computation in Lim \& Lee C. in preparation.

\subsection{Tentative solution}

To account for the exceptional licensing of caki under -te-, following Schlenker 2003 and Anand \& Nevins 2004, we assume that attitude predicates, such as malha'say', introduce their own context against which the embedded proposition is evaluated. For example, schematically, the LF with the attitude holder Bill and the attitude predicate malha- can be represented as in (34), where the utterance context is $c^{*}$ and the context introduced by malha- is $c^{\prime}$ : 
Perspective Shifts of Korean Evidentials

$$
\left[c^{*}\left[\text { Bill ... }\left[\text { malha }-\left[c^{\prime} \ldots\right]\right]\right]\right]
$$

We further assume that, when -te- is used, it overwrites not only the context $c^{*}$ for the prejacent, but also the context $c^{\prime}$ for the propositional complement of the attitude predicate in a 'global' manner (we do not specify the definedness condition for the context $c$ introduced by -te-):

$$
\begin{aligned}
& {\left[- \text { te }-\left[c^{*}\left[\text { Bill } \ldots\left[\text { malha }-\left[c^{\prime} \ldots\right]\right]\right]\right]\right]} \\
& =[\lambda c[\underline{c}[\text { Bill ... }[\text { malha }-[\underline{c} \ldots]]]]]
\end{aligned}
$$

Finally, Korean caki and PRO are bound by an operator introduced by the attitude predicate, as commonly assumed in previous studies of de selde te pronouns (Chierchia 1989 and Anand 2006, among others). However, rather than abstracting the utterer parameter in the context, we posit the following definedness condition for caki/PRO to be bound by an operator (in the same way as the presupposition of bound pronouns proposed in Heim 2008):

(36) $c a k i / P R O$ can be used as de selde te anaphor only when the utterer of the context has knowledge about the identity of the antecedent of caki/PRO (or relevant de selde te knowledge). ${ }^{8}$

Given these assumptions, we can account for the exceptional licensing of caki/PRO under -te- as follows. Normally, the utterer of the embedded context $c^{\prime}$ becomes the attitude holder. In a scenario such as (30) and (32), the attitude holder Bill does not have relevant knowledge about the reference of caki/PRO. Therefore, in sentences like (31a) and (33a), the definedness condition for caki/PRO is not satisfied under the embedded context $c^{\prime}$, since the utterer of $c^{\prime}$ is Bill, who does not have the relevant de selde te knowledge. This explains why (31a) and (33a) are infelicitous under the given scenario. In cases where -te-is used, the utterer of the embedded context is not the attitude holder, but the evidence holder in the bound context variable $c$, which is eventually saturated to the utterer's context $c^{*}$. In our scenarios, since this utterer has the relevant knowledge about the reference of caki/PRO, the definedness condition is satisfied by the evidence holder, and therefore caki/PRO can be licensed.

Before concluding this section, we also need to address one issue. The main motivation for the context overwriting in Anand \& Nevins 2004 was to argue against Schlenker's (2003) account for the shift of indexicals, which is based on the lexical ambiguity of indexicals (that is, whether an indexical is anchored to the context introduced by an attitude predicate or to the utterance context) and to explain the

8 This approach implies that $c a k i$ and PRO are treated as usual pronouns with a definedness condition, not pronouns specialized to the utterer or to the addressee of the context. At the moment we do not know what the conclusion or the possible prediction of this approach might be. 
indexical shifting in certain languages based on the context overwriting operator. In this paper we assume the various types of context overwriting, which naturally leads us to asking: what happens to the indexicals in Korean? It is beyond the scope of this paper to answer this question in detail, but we simply assume that Korean indexicals are always dependent on the utterance context $c^{*}$ (or we may assume that Korean indexicals have to be anchored to the context introduced by the sentential ending, such as the declarative ending in (28), which is always anchored to the utterance context $c^{*}$ ). This assumption is plausible given that in Korean indexicals never shift (see Lim 2010: cf. Byun 2008), but this may also mean that we need both the context overwriting (a la Anand \& Nevins 2004, among others) and (crosslinguistic) lexical ambiguities for indexicals (a la Schlenker 2003, among others). At the moment we do not know what the further empirical/theoretical implications of this assumption might be, and we leave this issue for future research. ${ }^{9}$

\section{Conclusion}

In this paper we discussed two types of evidential perspective shift in Korean, and argued that they can receive a unified analysis if we assume that Korean evidentials are functions taking either a proposition (in cases of -te-) or a character (in cases of -ray) as their arguments and returning a character. We also argued that Korean evidentials overwrite contexts of their prejacent, and discussed how this contextoverwriting effect interacts with the interpretation of Korean long-distance anaphor caki/PRO.

We conclude our paper by discussing one theoretical implication our paper has. We analyze Korean evidentials as functions taking a proposition (in cases of -te-) or a character (in cases of -ray) as their argument and returning a character. This means they are not spatiotemporal deictic tenses in the sense of Faller 2004 (contra what Chung (2007) claims regarding -te-), illocutionary operators in the sense of Faller 2002 (see the discussion in Lim 2010), or epistemic modals (contra what Lee J. (2010) claims regarding -te-). We believe that many previous studies of evidentials in the area of formal semantics simply try to 'assimilate' the grammatical category of an evidential under investigation to one of the three preexisting categories (epistemic modals, illocutionary operators, or deictic tenses: see Matthewson, Davis \& Rullmann 2007), and in cases of Korean evidentials there is no exception. However, our study shows that we should not be satisfied with that. We need to consider empirical differences between languages more seriously, and if we do so, it seems

9 One possible alternative is that what is overwritten by an evidential marker in Korean is not the context itself, but just a judge or assessor parameter, as argued in McCready 2007. However, we are not convinced that the requirement of the judge parameter is empirically enough supported: see von Fintel \& Gillies 2008, among others. 
Perspective Shifts of Korean Evidentials

reasonable to conclude that there can be more than these three preexisting lexical categories for evidentials: different languages may have different types of grammatical categories for evidentials.

\section{References}

Anand, Pranav. 2006. De De Se: Massachusetts Institutes of Technology dissertation.

Anand, Pranav \& Andrew Nevins. 2004. Shifty operators in changing contexts. In R. Young (ed.), Proceedings of Semantics and Linguistic Theory 14, 20-37. Ithaca: CLC Publications.

Byun, Hyuna. 2008. Logophoricity vs. indexical shifting of person pronouns in Korean. Handout presented at Penn Linguistic Colloquium 32.

Chae, Hee-Rhak. 2006. Yunghap hyensangkwa '(-ko) ha-'uy kwanlyenseng: [tay]hyeng phyohyenuy pwunsekul cwungsimulo (Fusion and (-ko) ha-: Focusing on the [tae]-type expressions). Language and Information 10(1). 1-20.

Chierchia, Gennaro. 1989. Anaphora and attitudes de se. In Renate Bartsch, Johan van Benthem \& Peter van Emde Boas (eds.), Language in context, 1-32. Dordrecht: Foris.

Chung, Kyung-Sook. 2007. Spatial deictic tense and evidentials in Korean. Natural Language Semantics 15. 187-219.

Chung, Kyung-Sook. 2010. Korean evidentials and assertion. Lingua 120. 932952.

Faller, Martina. 2002. Semantics and Pragmatics of Evidentials in Cuzco Quechua: Stanford University dissertation.

Faller, Martina. 2004. The deictic core of 'non-experienced past' in Cuzco Quechua. Journal of Semantics 21. 45-85.

von Fintel, Kai \& Anthony S. Gillies. 2008. CIA leaks. Philosophical Review 117(1). 77-98.

Garrett, Edward. 2001. Evidentiality and Assertion in Tibetan: University of California Los Angeles dissertation.

Hamblin, C. L. 1973. Questions in Montague English. Foundations of Language 10. 41-53.

Heim, Irene. 2008. Features on bound pronouns. In Daniel Harbour, David Adger \& Susana Béjar (eds.), Phi Theory, 35-56. Oxford: Oxford University Press.

Heim, Irene \& Kai von Fintel. 2001. Class notes. 'Advenced Semantics', MIT.

Hoe, Semoon. in preparation. Obligatory control constructions in Korean. Ms., Seoul National University.

Kaplan, David. 1989. Demonstratives. In Joseph Almog, John Perry \& Howard 
Wettstein (eds.), Themes from Kaplan, 481-563. Oxford: Oxford University Press.

Karttunen, Lauri. 1977. Syntax and semantics of questions. Linguistics and Philosophy 1(1). 3-44.

Lee, Chungmin. 2011. Evidentials: interactions and perspective shifts in Korean. Paper presented in ESSLLI 2011.

Lee, Jungmee. 2010. The Korean evidential -te: A modal analysis. In O. Bonami \& P. Cabrero Hofherr (eds.), Empirical Issues in Syntax and Semantics 8, 287311. CSSP.

Lim, Dongsik. 2010. Evidentials and Interrogatives: A case study from Korean: University of Southern California dissertation.

Lim, Dongsik. in preparation. Questions, characters, and evidentiality: a case study from Korean. Manuscript, USC \& CCHS-CSIC.

Lim, Dongsik. to appear. Temporal and inferential interpretation of Korean direct evidential -te-. In Proceedings of the 47th Chicago Linguistics Society, Chicago: Department of Linguistics, University of Chicago.

Lim, Dongsik \& Chungmin Lee. in preparation. Perspective shifts of Korean evidentials and context overwriting. Manuscript, CCHS-CSIC and Seoul National University.

Matthewson, Lisa, Henry Davis \& Hotze Rullmann. 2007. Evidentials as epistemic modals: evidence from St'át'imcets. Linguistic Variation Yearbook 7. 201-254.

McCready, Eric. 2007. Context shifting in questions and elsewhere. In E. PuigWaldmüller (ed.), Proceedings of Sinn und Bedeutung 11, 418-432. Universitat Pompeu Fabra.

Murray, Sarah. 2009. A Hamblin semantics for evidentials. In Satoshi Ito \& Ed Cormany (eds.), Proceedings of Semantics and Linguistic Theory 19, 324-341. Ithaca: CLC Publications.

Schlenker, Philippe. 2003. A plea for monsters. Linguistics and Philosophy 26. 29-120.

Schlenker, Philippe. 2007. The expressive presupposition. Theoretical Linguistics 33(2). 237-245.

Tenny, Carol. 2006. Evidentiality, experiencers, and the syntax of sentience in Japanese. Journal of East Asian Linguistics 15. 245-288.

Dongsik Lim

Calle de Albasanz 26-28

Madrid, Spain 28037

dongsik.lim@gmail.com
Chungmin Lee

Gwanakro 1, Gwanakgu

Seoul, South Korea

clee@snu.ac.kr 